\title{
Mast cell sarcoma of the larynx
}

\author{
H-P HORNY,* MR PARWARESCH,* E KAISERLING,* K MÜLLER, $\dagger$ \\ M OLBERMANN, $\dagger$ K MAINZER, $\ddagger$ K LENNERT
}

From the *Institute of Pathology, Christian-Albrecht University, Kiel, the †University of Mainz, Department of Medicine, and $\ddagger$ Allgemeines Krankenhaus Altona, Department of Medicine, Hamburg, West Germany

SUMMARY A 74 year old woman presented with a primary subglottic tumour. Neither cutaneous $\stackrel{\bar{\omega}}{\circ}$ mastocytosis (urticaria pigmentosa) nor spread to the bone marrow, liver, or spleen were detected. $\frac{\bar{g}}{8}$ About two years after initial manifestation of the tumour nodular skin metastases appeared, as well $\omega_{0}$ as local recurrence in the larynx. Despite chemotherapy and radiation the disease progressed and $\sigma_{0}$ was fatal. The terminal phase was characterised by generalisation of the mast cell tumour with $\mathcal{C}_{0}$ diffuse infiltration of bone marrow and, shortly before death, leukaemic transformation. The

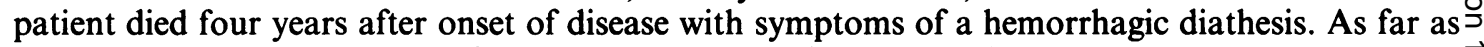
we know this is the first case of mast cell sarcoma to be reported in man.

Neoplasms of the tissue mast cell system are rare. A basic distinction is made between generalised or systemic mastocytosis and urticaria pigmentosa, which is regarded as a purely cutaneous mastocytosis with macular, maculopapular, and less often, bullous ${ }^{1}$ or telangiectatic ${ }^{2}$ skin lesions. Whether or not the skin is affected, generalised mastocytosis always shows infiltration of extracutaneous tissues (usually bone marrow and often spleen, liver, or lymph nodes). Although the prognosis of urticaria pigmentosa is favourable, especially in childhood, ${ }^{3}$ it is usually impossible to predict reliably the prognosis in cases of generalised mastocytosis. Recently, we showed that primary skin disease in generalised mastocytosis indicates a relatively good prognosis. ${ }^{4}$ This type of systemic mastocytosis must be clearly distinguished from malignant systemic mastocytosis. Although malignant mastocytosis does not entail primary skin disease, it often coincides with myeloproliferative disorders, especially chronic myeloid leukaemia, or presents as overt mast cell leukaemia. ${ }^{5}$ Thus the prognosis for malignant mastocytosis is generally poor. Primary localised mast cell sarcoma has not been described in published reports. ${ }^{6}$ The following detailed description covers its nosological relation to other mastocytic neoplasms.

Accepted for publication 16 December 1985

\section{Case report}

In May 1970 a 71 year old woman complained of hoarseness. A subglottic mass was detected in August 1970. A chronic inflammatory process was diagnosed on a biopsy specimen of the tumour. The lesion did not respond to treatment with antibiotics and corti- $\mathbb{\perp}$ costeroids. The tumour was therefore completely $\overrightarrow{\overrightarrow{\vec{A}}}$ removed early in 1971. Histology was first interpreted $\frac{\circ}{3}$ as "resembling Wegener's granulomatosis." Accordingly, the patient was treated with cortisone untilo March 1972. Two bluish-red protruding tumours, each $4 \mathrm{~cm}$ in diameter, appeared on her back and upper arm in January 1972. Histological and electron $\frac{0}{3}$ microscopic analyses of these tumours established a diagnosis of mast cell sarcoma.

In March 1972 clinical examination showed bilat- $₹$ eral enlargement of submandibular and axillary lymph nodes (about $2 \mathrm{~cm}$ in diameter). In the skin of $D$ the upper medial quadrant of each breast bluish, firm, slightly raised nodules $(0.5 \mathrm{~cm}$ and $1.5 \mathrm{~cm}$ in diameter) had appeared. All other physical findings were normal; the liver and spleen, in particular, were not 0 enlarged. Laboratory tests showed an erythrocyte $N_{\omega}$ sedimentation rate of $18 /$ first hour and 38/second hour, an erythrocyte count of $4.8 \times 10^{6} / \mathrm{mm}^{3}$, a hae-e moglobin concentration of $14.3 \mathrm{~g} / \mathrm{dl}$, and a leucocyte count of $6300 / \mathrm{mm}^{3}$, with $3 \%$ stab cells, $59 \%$ poly- $\stackrel{\oplus}{?}$ morphonuclear cells, $1 \%$ eosinophils, $4 \%$ monocytes, and $33 \%$ lymphocytes. The platelet count was $216000 / \mathrm{mm}^{3}$. Examination of a bone marrow smear $\stackrel{\mathbb{Q}}{\overparen{P}}$ showed intact granulocytopoiesis and erythropoiesis $\stackrel{\mathbb{Q}}{\mathscr{Q}}$ and no increase in mast cells. Histological analysis of 
a trephine biopsy specimen of iliac crest and a liver puncture ruled out mast cell infiltration. No increase in heparin activity could be detected in either serum or urine. A severely increased 24 hour histamine excretion rate, however, was found in two urine samples taken in March and July 1972 (1510 and $860 \mu \mathrm{g}$, respectively; normal value $60 \mu \mathrm{g}$ ).

In March 1973 firm nodular skin infiltrates appeared on her back. In June 1973 similar nodules were found in the skin of both breasts and both flanks. There was also local recurrence of the subglottic tumour. Diagnosis of mast cell sarcoma was confirmed on biopsy specimens of these lesions. A trephine biopsy of iliac crest performed at this time and cytological analysis of sternal marrow did not show mast cell infiltrates. Progression of the disease made it necessary for the patient to receive systemic treatment with bleomycin (total dosage $285 \mathrm{mg}$ over six weeks). During the course of this treatment, however, the skin infiltrates and subglottic tumour increased in size. Subsequent telecobalt irradiation of a few foci brought rapid, though only temporary, remission of all (even untreated) infiltrates of the skin and larynx. By December 1973, however, the skin infiltrates had reappeared. Once again the patient underwent chemotherapy according to a modified DeVita regimen, and the metastases receded surprisingly quickly.

In May 1974 the general condition of the patient deteriorated. A bluish-red skin tumour about $10 \mathrm{~cm}$ in diameter appeared in the right buttock. Clinical examination showed hepatosplenomegaly and generalised lymphadenopathy. Laboratory findings included: erythrocyte sedimentation rate $74 /$ first hour and $95 /$ second hour, erythrocytes $4.5 \times 10^{6} / \mathrm{mm}^{3}$, haemoglobin concentration $14 \mathrm{~g} / \mathrm{dl}$, and leucocytes $11200 / \mathrm{mm}^{3}$, with $90 \%$ atypical mast cells. The platelet count was $30500 / \mathrm{mm}^{3}$. A hypocellular sternal marrow smear showed infiltration by atypical immature mast cells concurrent with severe hypoplasia of the normal blood cell precursors. A trephine biopsy specimen of iliac crest taken at the same time showed diffuse infiltration of the bone marrow by neoplastic mast cells. Infiltrates of atypical mast cells were also detected in a lymph node biopsy specimen.

The patient died in May 1974 of circulatory failure after four years of disease. The terminal phase was characterised by symptoms of acute haemorrhagic diathesis. Necropsy findings included grey-red marrow in the sternum, spine, and right femur, severe hepatosplenomegaly (liver $3000 \mathrm{~g}$, spleen $520 \mathrm{~g}$ ), and an ulcerated skin tumour $(10 \mathrm{~cm}$ diameter $)$ in the right buttock. There were also nodular grey-white infiltrates in both kidneys, generalised lymphadenopathy, pronounced pallor of the viscera and pulmonary oedema.

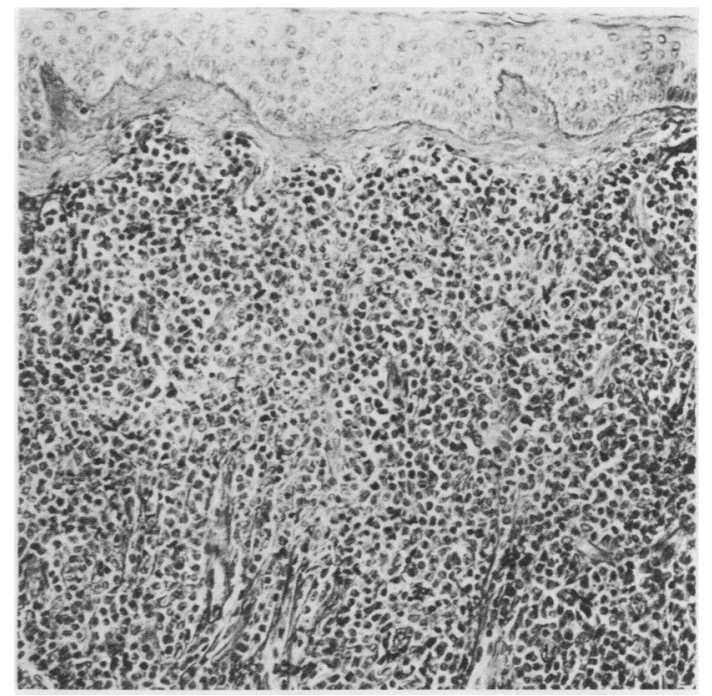

Fig. 1 Diffuse infiltration of dermis by atypical mast cells. Epidermis is intact (Periodic acid Schiff.) $\times 140$.

\section{Material and methods}

Specimens for light microscopic examination were fixed in $10 \%$ formalin and embedded in paraffin. The sections were stained with the following methods: haematoxylin and eosin, periodic acid Schiff, Gömöri's silver impregnation, Giemsa, toluidine blue, and naphthol AS-D chloroacetate esterase. ${ }^{7}$ Lymph node imprints and blood smears were subjected to the fol-

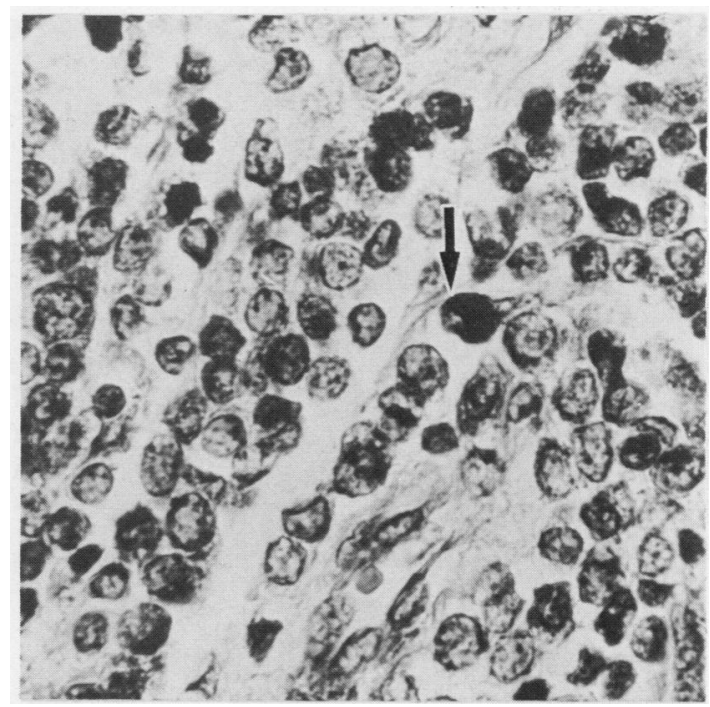

Fig. 2 Infiltrates of slightly pleomorphic mast cells in deeper dermis. Some tumour cells are darkly stained (arrow) by chloroacetate esterase reaction. $\times 250$. 


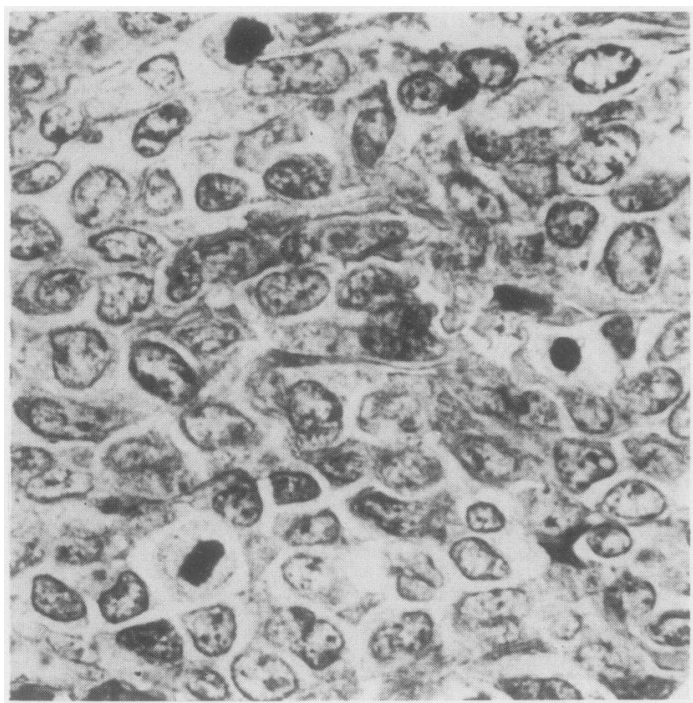

Fig. 3 Dense infiltrates consisting of pleomorphic mast cells in soft tissue of thigh. There are numerous mitotic figures.

Some nuclei are indented (Giemsa.) $\times 560$.

lowing staining procedures: Pappenheim, toluidine blue, and naphthol AS-D chloroacetate esterase reaction. For electron microscopic examination tissue was fixed in $5 \%$ buffered glutaraldehyde and then fixed in $1 \% \mathrm{OsO}_{4}$ (Rhodin buffer, $\mathrm{pH} \mathrm{7 \cdot 3)}$. After embedding in araldite ultrathin sections were stained with uranyl acetate followed by Reynold's lead citrate and examined under a Siemens Elmiskop I at $80 \mathrm{KV}$.

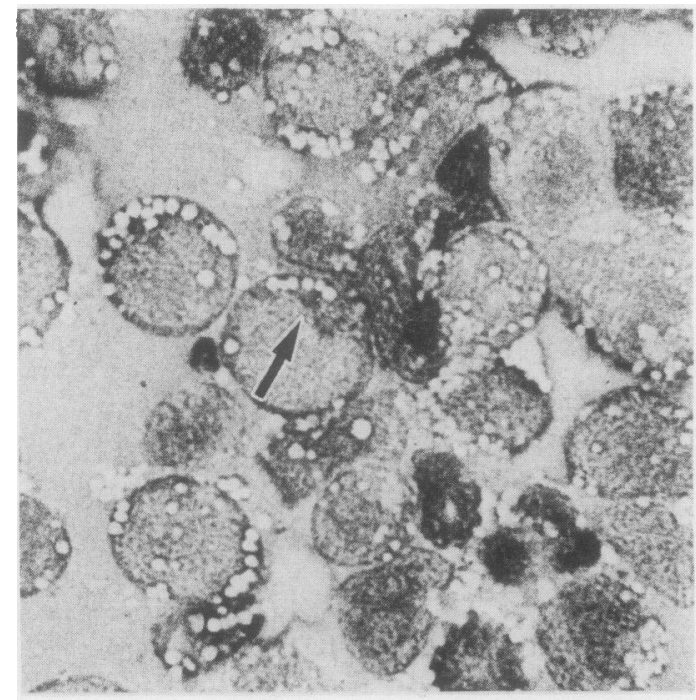

Fig. 4 Tumour of right groin. Imprint with atypical mast cells showing vacuolated cytoplasm. Few tumour cells contain metachromatic granules (arrow) (Pappenheim.) × 560 .

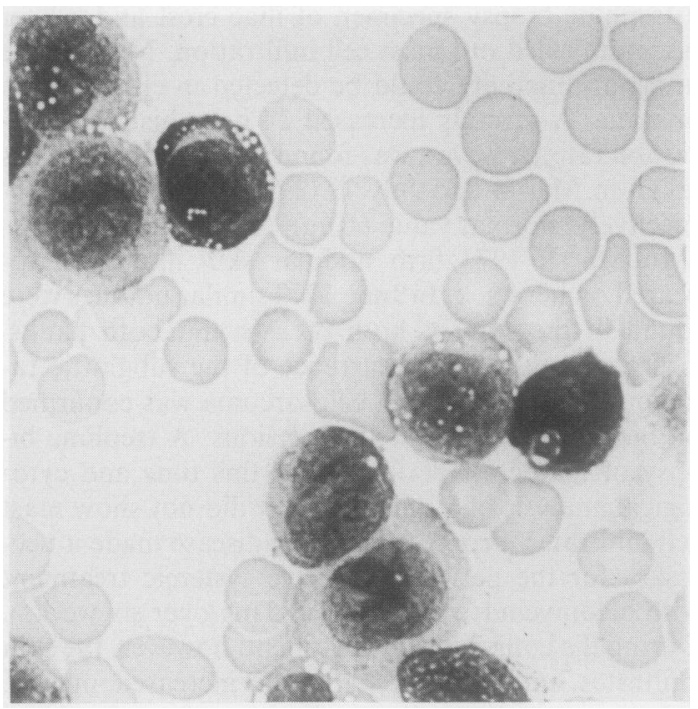

Fig. 5 Blood smear showing many atypical mast cells, some with indented "monocytoid" nuclei (Pappenheim.) $\times 560$.

\section{LIGHT MICROSCOPIC FINDINGS}

Biopsy of the larynx (August 1971; R-1393/72) Theo mucosa was intact, whereas the submucosa was diffusely infiltrated by slightly pleomorphic mediumō sized cells. The nuclei often showed an irregular out-气ू line with occasional indentation. Giemsa and tolu- $\triangle$ idine blue staining showed that some tumour cells $\vec{\circ}$ contained metachromatic granules. Most tumour3 cells exhibited a strongly positive reaction with the naphthol AS-D chloroacetate esterase procedure. Reticulin fibres were arranged in an alveolar pattern. Mast cell sarcoma of the larynx was diagnosed.

Skin biopsy of the back (January 1972; R-1398/72) 3 The epidermis seemed to be intact with an underlying band shaped fibrosis. The dermis was destroyed by an 3 extensive infiltrate consisting of slightly pleomorphic tumour cells (Fig. 1). About $50 \%$ of the atypical cells showed high reactivity with naphthol AS-D chloro- $\frac{7}{0}$ acetate esterase (Fig. 2), while only few tumour cells contained metachromatic granules. Mitotic activity was low. Skin metastasis of a mast cell sarcoma was diagnosed.

Biopsy of the right thigh (December 1973; R-2740/73) A dense nodular infiltrate consisting of highly pleomorphic tumour cells dominated the histological pic-읃 ture (Fig. 3). Numerous large cells with scanty nuclear chromatin and prominent, often single nucleoli were ${ }^{-}$ interspersed with smaller cells, some of which con- $\frac{0}{0}$ tained scanty metachromatic granules. There were्⿱ numerous mitotic figures. Roughly $20 \%$ of the tumour cells showed weak reactivity with naphthol AS-D chloroacetate esterase. Reticulin fibres were in? 


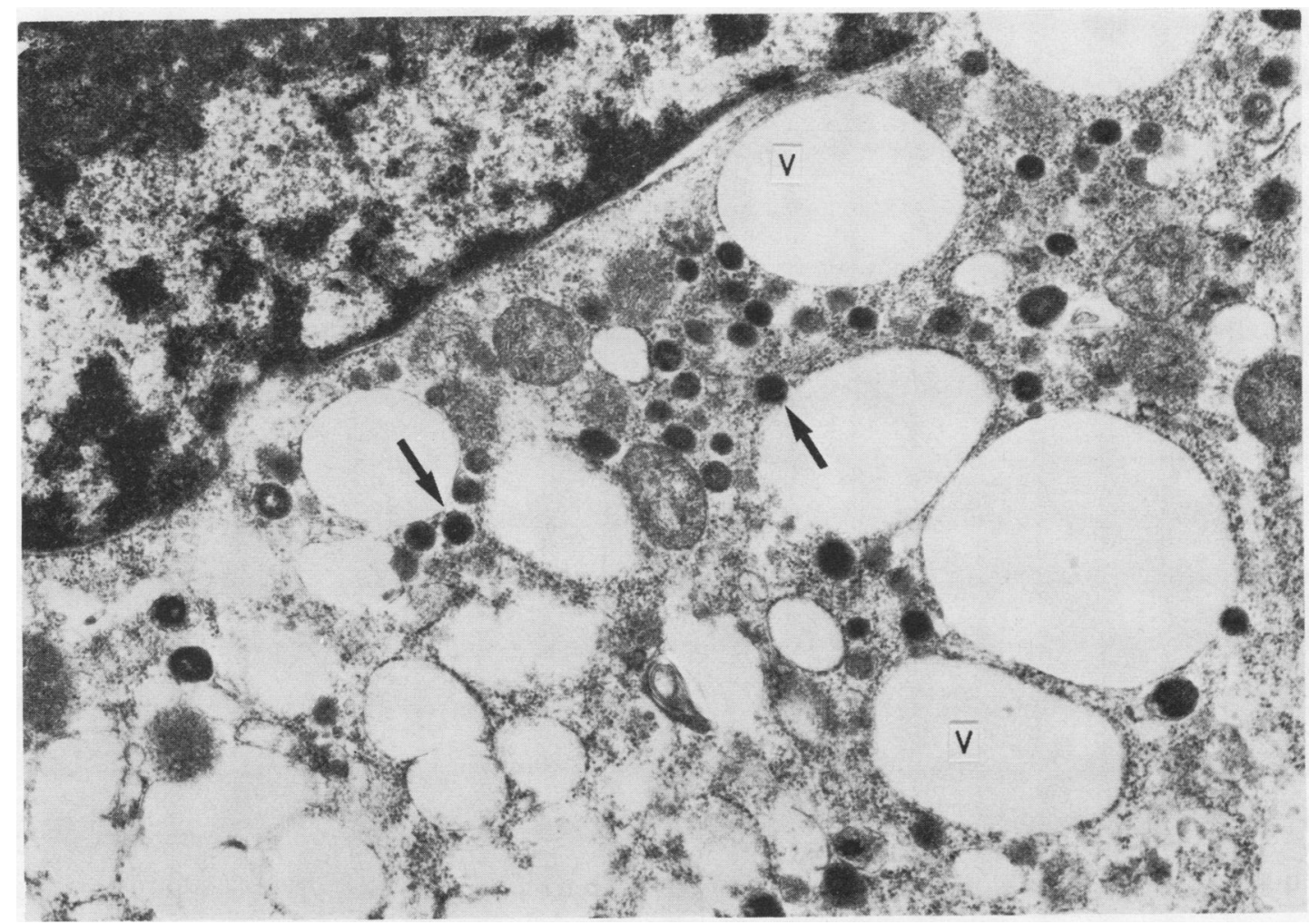

Fig. 6 Tumour cell showing irregular nuclear configuration and numerous mostly electron dense granules (arrows) in electron transparent vacuoles $(V)$ and cytoplasm. $\times 21000$.

terspersed throughout. Anaplastic metastasis of mast cell sarcoma was diagnosed.

Tumour of the right groin (May 1974; R-1498/74) Histology showed dense infiltrates consisting of medium sized to large tumour cells with reniform nuclei. Nuclear chromatin was scanty. Toluidine blue staining showed no metachromatic granules. Naphthol AS-D chloroacetate reaction was positive in only a few cells. High mitotic activity was present. The imprint of the tumour was dominated by cells with blue cytoplasm containing many vacuoles. Few cells showed small metachromatic granules (Fig. 4). Anaplastic metastasis of mast cell sarcoma was diagnosed.

Blood smear (May 1974; R-1498/74) Atypical cells with indented "monocytoid" nuclei comprised the largest portion of the nucleated cells (Fig. 5). Some of them contained metachromatic granules. Differential count: $89 \%$ atypical mast cells, $1 \%$ myelocytes, $2 \%$ stabs, $4 \%$ neutrophils, $2 \%$ eosinophils, $2 \%$ lymphocytes; in addition erythroblasts were seen. Mast cell leukaemia (leukaemic transformation of mast cell sarcoma) was diagnosed.

\section{ELECTRON MICROSCOPIC FINDINGS}

Skin biopsy of the neck (March 1973; R-719/73) Electron microscopic examination (Figs. 6 and 7 ) showed tumour cells scattered either singly among collagenous fibres or arranged in groups of three to five cells each. Infiltration of perivascular areas was not uncommon. The tumour cells exhibited irregular nuclei; some were invaginated, others had a serrated outline. Dispersion of heterochromatin was generally uniform, although occasional condensation into small clumps occurred. The tumour cells had one, but also often two, centrally located nucleoli. Granules of varying size and number were scattered throughout the cytoplasm. In some cells the granules were found in the area of the nuclear invagination (Fig. 7) or in the vicinity of the Golgi apparatus.

Most of the granules were extremely electron dense and amorphous, although transitional forms from the least to the most electron dense granules, with an increasing granular appearance, could be found. There were, accordingly, also granules with a central amorphous and a peripheral granular component (compound granules). Only a few empty granule spaces 


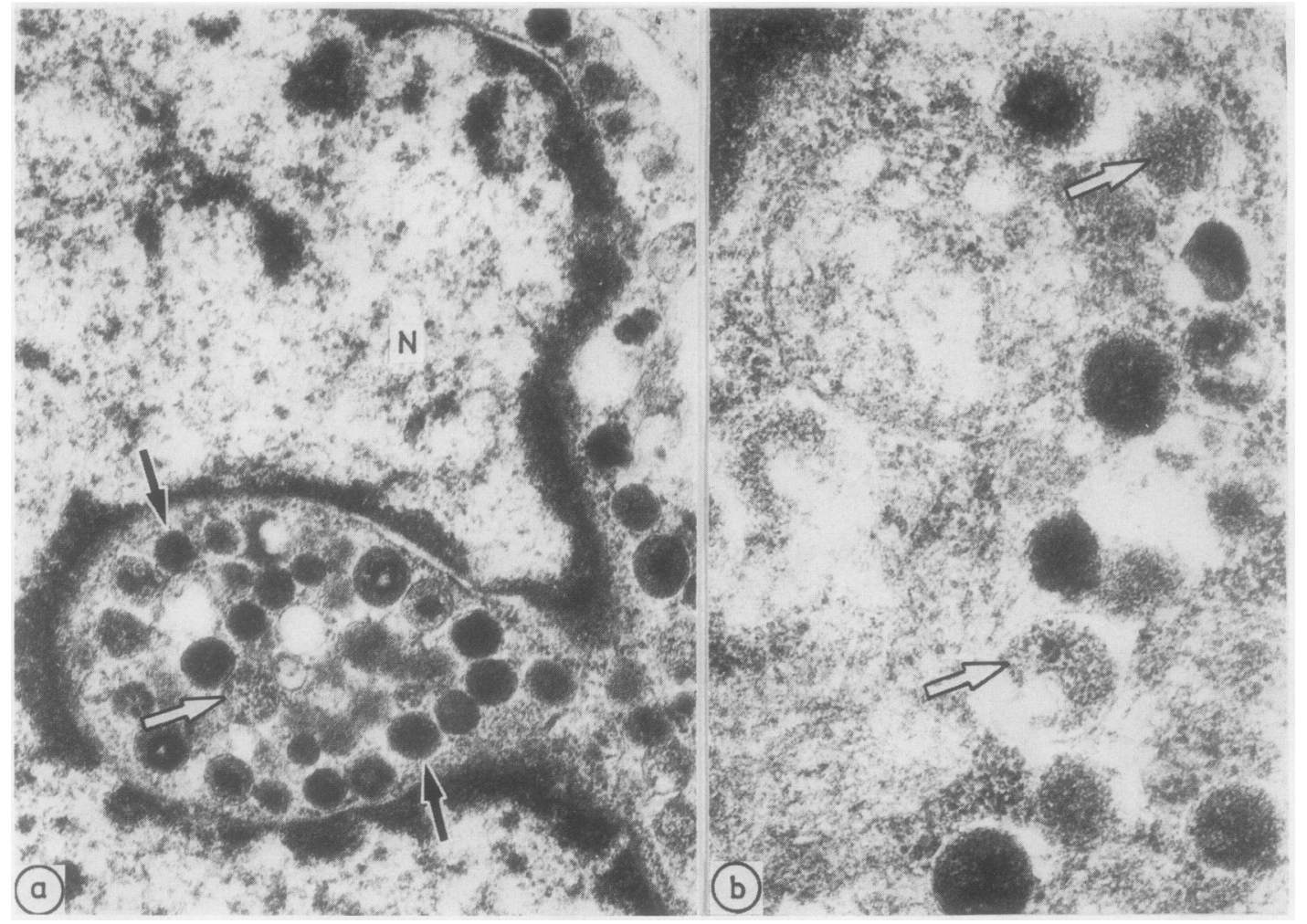

Fig. 7 (a) Closely grouped granules of various electron densities in region of nuclear invagination (b). There are amorphous granules (arrows) and granules with granular architecture (open arrows). $N=$ Nucleus. $(a) \times 26000 ;(b) \times$ 55000

were found. Crystalline granules with parallel laminae forming scrolls and cylinders were not found. The granules measured $0.5 \mu \mathrm{m}$ in diameter on average.

Other structures in the cytoplasm included a Golgi apparatus and a few very small usually moderately electron dense granules near the nucleus, coated vesicles, numerous monoribosomes, and a few strands of rough endoplasmic reticulum. A few scattered cells were remarkable for their large number of cytoplasmic vacuoles.

Tumour of the right groin (May 1974; R1498/74) The biopsy specimen taken in 1974 shortly before death presented a fundamentally different picture compared with that of the previous biopsy. The tumour cells often exhibited an oval nucleus and a high nucleocytoplasmic ratio (Fig. 8). The cytoplasm contained few very small granules with severe to moderate electron density. Accordingly, amorphous or granular material containing granules could not be distinguished. The granules were strewn unevenly throughout the cytoplasm, exhibiting no preference for the Golgi region. The diameter of the granules was always less than
$0.5 \mu \mathrm{m}$-that is, less than in previous biopsy specimens. The mast cells in the earlier biopsy specimen contained from 20 to 100 granules per cell, whereas: now only 15 to 20 granules at most could be found 3 The Golgi apparatus was somewhat larger than that found in cells of the previous biopsy specimen Tumour cells also contained numerous lipid droplets

\section{Discussion}

A primary localised mast cell sarcoma of the larynx $\times$ was diagnosed. The diagnosis was confirmed by histo 70 chemical and electron microscopic studies. Histo는 chemically, metachromatic granules were detected in the tumour cells, and the naphthol AS-D chloror acetate esterase reaction was clearly positive. This las finding must be regarded as a strong indication of the mast cell nature of the tumour. ${ }^{7}$ Appropriate biopsy controls ruled out mast cell infiltration of other organs, especially as the bone marrow was free of mastocytic infiltrates. No sign of cutaneous mast $\frac{?}{\mathrm{D}}$ ocytosis (urticaria pigmentosa) could be detected? The course of the disease was characterised by sarco 


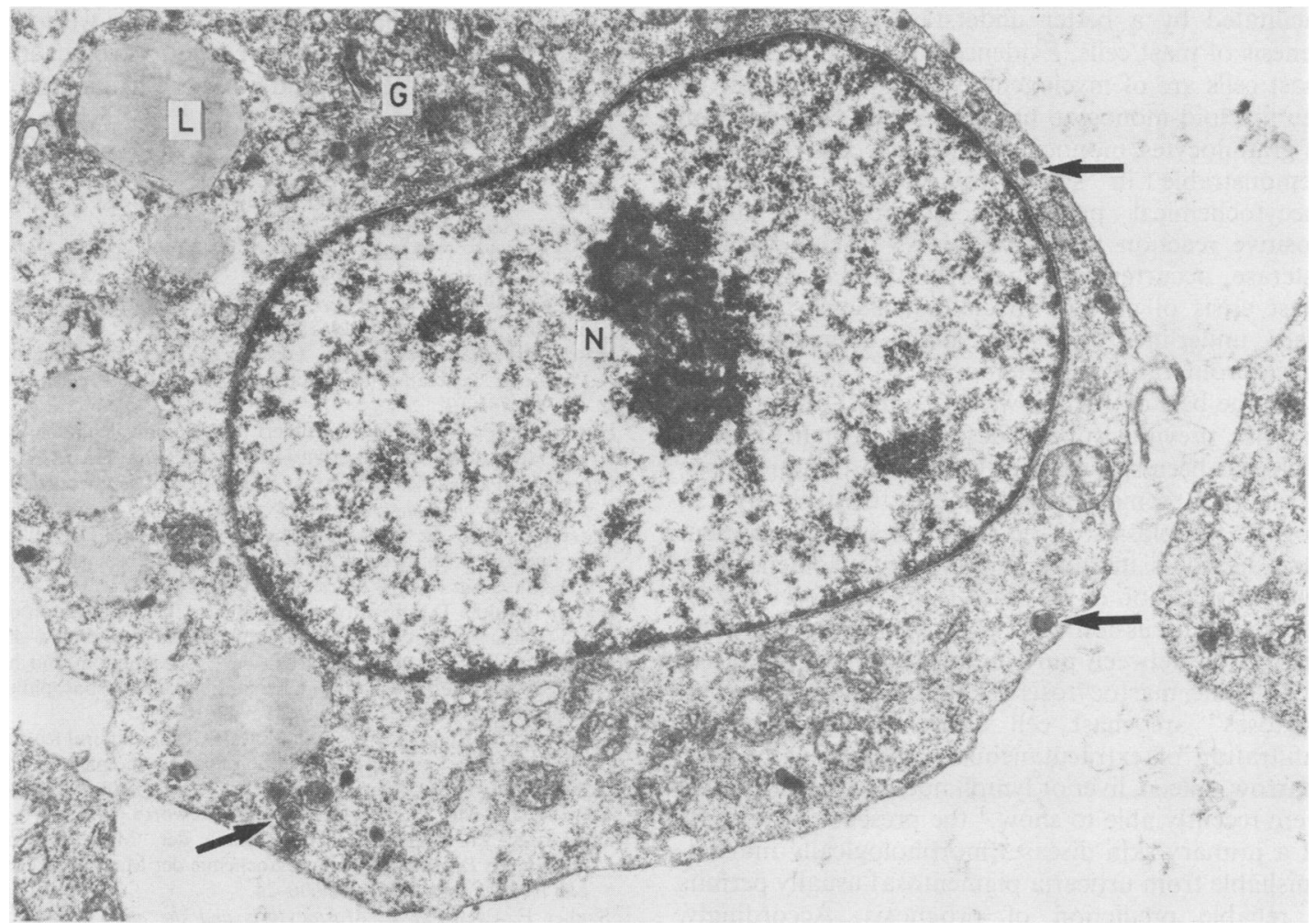

Fig. 8 Tumour cells from biopsy specimen taken shortly before death. Cytoplasm contains only very few granules (arrows). Notable are the extensive Golgi field $(G)$, some lipid droplets $(L)$, and prominent nucleus $(N)$ with large nucleolus. $\times 13000$.

matous skin metastases. Chemotherapy and radiation achieved only temporary arrest of the disease. The terminal phase was complicated by a generalisation of the mast cell tumour, with infiltration of spleen, lymph nodes, and bone marrow. Shortly before death a leukaemic transformation developed with atypical mast cells in the blood. The patient died four years after onset of the disease with signs of haemorrhagic diathesis.

Light and electron microscopic findings were correlated with the clinical progress of the disease. Sequentially taken biopsy specimens showed increasing anaplasia of the mast cells. Initially, most of the tumour cells showed a severe naphthol AS-D chloroacetate esterase reaction, whereas in the later stages fewer cells were positive. Metachromatic granules could be clearly verified only in the early stages of the disease, although in the terminal phase only a minority of the neoplastic mast cells contained a very small number of such granules. Cytologically, increasing pleomorphism of the mast cells and of mitotic activity was observed. Dedifferentiation was also clearly noticeable ultrastructurally, with a decrease in granular content, size, and density. Combined, these findings confirmed the diagnosis of primary localised mast cell sarcoma with increasing anaplasia.

That the leukaemic terminal event represents a true leukaemic transformation of a primary localised mast cell tumour is supported by the exclusion of mastocytic infiltrates in other tissue sites, especially in organs commonly affected by mastocytosis (skin, bone marrow, spleen, liver, and lymph nodes) in the initial phase of the disease. The occurrence of this unique phenomenon in a sarcoma of soft tissues is

Table Neoplasias of tissue mast cell system 
facilitated by a better understanding of the cytogenesis of mast cells. Evidence has accumulated that mast cells are of myelogenous origin, evolving from the myeloid-monocyte lineage. ${ }^{68}$ The close relation of granulocytes, monocytes, and mast cells is not only demonstrable in shared cytological and enzymecytochemical properties (erythrophagocytosis, ${ }^{9}$ positive reaction for naphthol AS-D chloroacetate esterase, occurrence of mastocytic differentiation in blast crisis of chronic myeloid leukaemia ${ }^{9}$ ), but is also underlined by the high coincidence of myeloproliferative disorders .

To the best of our knowledge, a mast cell sarcoma has not previously been described in man, though there has been speculation that such a tumour exists. Mast cell sarcomas, however, occur relatively often in dogs. ${ }^{10}$ Neoplasias of the mast cell system represent rare disorders in human pathology. Nomenclature and classification of the various mastocytoses are the subject of discussion. ${ }^{10-12}$ There is, however, a clear distinction between pure cutaneous and generalised, or systemic, mastocytosis (Table). "Generalised mastocytoses" are mast cell tumours with polytopic infiltration of extracutaneous organs (usually bone marrow, spleen, liver or lymph nodes, or both). As we were recently able to show, ${ }^{4}$ the presence or absence of a primary skin disease (morphologically indistinguishable from urticaria pigmentosa) usually permits a reliable prediction of prognosis. Accordingly, patients with primary skin disease have a generally favourable prognosis. Patients without skin disease are designated as having "malignant systemic mastocytosis," because the disease runs a much more aggressive and rapidly fatal course. The unfavourable prognosis in these patients can be explained by the high coincidence of malignant mastocytosis with my- $\stackrel{0}{=}$ eloproliferative disorders (especially chronic and으․ acute myeloid leukaemia) and mast cell leukaemia. ${ }^{13} \vec{\Rightarrow}$

References

${ }^{1}$ Orkin M, Good RA, Clawson CC, Fisher I, Windhorst D. Bullouş mastocytosis. Arch Dermatol 1970;547:547-64.

${ }^{2}$ Parkes Weber F, Hellenschmied R. Teleangiectasia macularis erup tiva perstans. Br J Dermatol 1930;42:374-82.

${ }^{3}$ Klaus SN, Winkelmann RK. Course of urticaria pigmentosa in children. Arch Dermatol 1962;86:68-71.

${ }^{4}$ Horny H-P, Parwaresch MR, Lennert K. Klinisches Bild und Prognose generalisierter Mastocytosen. Klin Wochenschicu 1983;61:785-93.

${ }^{5}$ Horny H-P, Parwaresch MR, Lennert K. Basophilenleukämie un generalisierte Mastocytose. Verh Dtsch Ges Path 1983;67:192-7

${ }^{6}$ Lennert K, Parwaresch MR. Mast cells and mast cell neoplasia: $x$ review. Histopathology 1979;3:349-65.

${ }^{7}$ Leder LD. Über die selektive fermentcytochemische Darstellund von neutrophilen myeloischen Zellen und Gewebsmastzellen imo Paraffinschnitt. Klin Wochenschr 1964;42:53.

${ }^{8}$ Zucker-Franklin D. Ultrastructural evidence for the common origin of human mast cells and basophils. Blood 1980;56:534-40. $\overrightarrow{-}$

${ }^{9}$ Brinkmann D. Mastzellenreticulose (Gewebsbasophilom) mit his $\subseteq$ taminbedingtem Flush und Úbergang in Gewebsbasophilen $-\frac{\bar{\Phi}}{\bar{D}}$ Leukämie. Schweiz Med Wschr 1959;89:1046-53.

${ }^{10}$ Parkin JL, McKenna RW, Brunning RD. Ultrastructural features $\overrightarrow{0}$ of basophil and mast cell granulopoiesis in blastic phase. Philadelphia chromosome-positive leukemia. JNCI 1980;65:535-46.

${ }^{11}$ Selye H. The mast cells. Washington: Butterworth, 1965.

${ }^{12}$ Lennert K. Zur pathologischen Anatomie der "Mastocytosen" mit einigen Bemerkungen zur Cytochemie der Mastzellen. Arch klin u exper Derm 1961;213:606-24. ${ }^{13}$ Sagher F, Even-Paz Z. Mastocytosis and the mast cell. Basel

${ }^{14}$ Horny H-P, Parwaresch MR, Lennert K. Bone marrow findings in systemic mastocytosis. Hum Pathol 1985;16:808-14.

Requests for reprints to: Dr H-P Horny, Institute of Pathology, Hospitalstrasse. 42, D-2300 Kiel 1, Wes? Germany. 